\title{
CORROSION FATIGUE CRACK GROWTH STUDIES ON PRESSURE VESSEL AND PIPING STEELS IN WATER ENVIRONMENT
}

\begin{abstract}
Corrosion fatigue crack growth studies were conducted on eccentrically-loaded single edge notch tension specimens made of SA 333 Gr. 6 and SA 516 Gr. 70 carbon steels in water environment. The experiments were conducted using a $\pm 250 \mathrm{kN}$ capacity Universal Testing Machine under constant amplitude sinusoidal loading at a test frequency of $0.50 \mathrm{~Hz}$ and stress ratio of 0.1 . The fabrication of test specimens and the experiments were carried out based on ASTM E 647 and ASTM E 1820. The crack initiation and growth were monitored and images were captured by using a digital camera at regular intervals of fatigue cycles. By using these images, the length of crack was measured. The tests were terminated when the uncracked portion of the specimens was insufficient to take further load. Crack growth rate and stress intensity factor range values were evaluated at incremental values of loading cycles and crack length. Using the crack growth rate vs. stress intensity factor range plots, best fit curves following power law in the form of Paris' equation were obtained.

Keywords: Fatigue crack growth, Corrosion fatigue, ESE(T) Specimen, SA 333 Gr.6 steel, SA 516 Gr.70 steel
\end{abstract}

\section{Introduction}

Corrosion fatigue is the phenomenon of cracking in a structure under combined action of fatigue and corrosive environment. As per ASTM E 742 [1], corrosion fatigue is defined as the 'synergistic effect of fatigue and aggressive environment acting simultaneously which leads to degradation in fatigue behavior'. Corrosion fatigue is an important phenomenon that can lead to unexpected cracking and ultimately failure of the structure. This phenomenon occurs in many engineering structures such as offshore structures, bridges, power plant structures and aircraft which are subjected to repetitive environmental and operational loads and has been recognized as an important cause of failure of the structures. Cyclic loading and deleterious environment, acting together, lead to formation of crack/s which grow over time and reduce the load carrying capacity of the structure; this in turn would ultimately cause the failure of the structure. Corrosion fatigue damage is a synergistic effect of fatigue and corrosion processes acting simultaneously, i.e., repeated stressing accelerates the corrosion action and corrosion action accelerates the fatigue damage of the structure. Because of this, the estimation of corrosion fatigue crack growth rate is of great importance in the life prediction and safety assessment of these structures.

J.Y. Huang et al. [2] carried out fatigue crack growth studies on compact specimens $[\mathrm{C}(\mathrm{T})]$ of A533B3 steels subjected to four levels of sulfur content at different temperatures in air and high temperature water environments under constant amplitude cyclic loading. Fatigue crack growth tests under constant amplitude load were performed with a $100 \mathrm{kN}$ closed loop servo-hydraulic machine at room temperature, $150^{\circ} \mathrm{C}, 300^{\circ} \mathrm{C}$ and $400^{\circ} \mathrm{C}$. It was concluded that the fatigue crack growth rates in oxygen-saturated water environment were faster than those obtained in air. There was no significant difference between the fatigue crack growth rates for the steels with various sulfur contents. The fatigue crack growth rate at $400^{\circ} \mathrm{C}$ was about two and half times faster than those tested in room temperature, $150^{\circ} \mathrm{C}$, and $300^{\circ} \mathrm{C}$. Chinnaiah Madduri and Raghu V. Prakash [3] conducted corrosion fatigue crack growth (CFCG) studies on $\mathrm{Ni}-\mathrm{Cr}-\mathrm{Mn}$ steel under $3.5 \%$ of saturated $\mathrm{NaCl}$ aqueous solution. The fatigue crack growth studies were conducted on a compact specimen under a constant amplitude cyclic loading. It was observed that there is an increase in the crack growth and reduction in the threshold stress intensity for the material when tested in 3.5\% saturated $\mathrm{NaCl}$ environment compared to data obtained under laboratory air condition. Jamasri et al. [4] conducted fatigue crack growth studies on resistance spot-welded dissimilar material with significant difference in thickness between austenitic stainless steel and carbon steel. Carbon steel SS 400 with thickness of $3 \mathrm{~mm}$ and austenitic stainless steel SUS 304 with thickness $1 \mathrm{~mm}$ were lap joined using resistance spot-welding. Fatigue crack growth

\footnotetext{
* VIT UNIVERSITY, VELLORE, INDIA

** FATIGUE \& FRACTURE LABORATORY, CSIR-STRUCTURAL ENGINEERING REASEARCH CENTRE, CHENNAI, INDIA

\# Corresponding author: neethumathew20@gmail.com
} 
studies were carried out in air and seawater environments at a frequency of $8 \mathrm{~Hz}$ and salinity of $34.5 \mathrm{~g} / \mathrm{L}$. Results showed that fatigue strength of resistance spot-welded specimen in sea water environment was less than fatigue strength in air. The endurance limit in air was $32 \mathrm{MPa}$, whereas corrosion fatigue samples at this stress failed at about 400,000 cycles. Raghava et al. [5] and Vishnuvardhan et al. [6] carried out corrosion fatigue crack growth experiments on eccentrically-loaded single edge notch tension [ESE(T)] specimens made of IS 2062 Gr. E 300 steel. The corrosion process was accelerated using an external current source by applying constant Direct Current (DC) of $0.1 \mathrm{~A}, 0.2 \mathrm{~A}$ and $0.3 \mathrm{~A}$. At each level of corrosion current, three specimens were tested at a loading frequency of $0.25 \mathrm{~Hz}, 0.50 \mathrm{~Hz}$ and $0.75 \mathrm{~Hz}$. All the experiments were carried out under constant amplitude sinusoidal cyclic loading and stress ratio of 0.1 . Results showed that decrease in fatigue life varied from $14 \%-42 \%$ when applied current increased from 0.1 A to $0.3 \mathrm{~A}$. The effect of corrosion current on fatigue life was observed to be more predominant at higher frequencies, i.e., $0.50 \mathrm{~Hz}$ and $0.75 \mathrm{~Hz}$ when compared with 0.25 Hz. Aarthi et al. [7] conducted accelerated corrosion fatigue crack growth studies on eccentrically-loaded single edge notch tension [ESE(T)] specimen made of SA 333 Gr. 6 steel. The corrosion process was accelerated by applying a direct current of $0.3 \mathrm{~A}$ using an external current source. The experiment was carried out under constant amplitude sinusoidal cyclic loading at a test frequency of $0.50 \mathrm{~Hz}$ and stress ratio of 0.1 by using $\pm 250 \mathrm{kN}$ capacity fatigue rated Universal Testing Machine. The specimen took 50,000 fatigue load cycles for the crack to initiate. The experiment was stopped at 1,19,302 cycles, when the specimen became unstable and the uncracked ligament was insufficient to take further load. The total crack growth during the experiment was $39.57 \mathrm{~mm}$.

Carrying out corrosion fatigue investigations in the laboratory at the same conditions at which the environment acts on the structure is time-consuming, and many studies on materials and structural components reported in literature have had been carried out for months and years. In this present study, fatigue crack growth experiments were carried out on SA 333 Gr. 6, SA $516 \mathrm{Gr} .70$ carbon steels under water environment. The tests were conducted at constant amplitude sinusoidal cyclic loading by using a $\pm 250 \mathrm{kN}$ capacity Universal Testing Machine (UTM). The test frequency was $0.50 \mathrm{~Hz}$ and the stress ratio was 0.1 . Details of the experimental study carried out and the fatigue crack growth data obtained during the experiments have been discussed. Crack growth rate $(d a / d N)$ and stress intensity factor range $(\Delta K)$ values were evaluated at incremental values of loading cycles and crack length. Using the crack growth rate $(d a / d N)$ vs. stress intensity factor range $(\Delta K)$ plots, best fit curves following power law in the form of Paris' equation were obtained.

\section{Material properties}

The steels used in present study were SA 333 Gr. 6 carbon steel and SA 516 Gr. 70 carbon steel conforming to ASTM A 333 [8] and ASTM A 516 [9] respectively. SA 333 Gr. 6 steel is used in the fabrication of primary heat transfer pipes used in nuclear power plant, operating at lower temperatures. SA 516 Gr. 70 steel is used throughout oil, gas, petrochemical industry. This material is known for its weldability and improved notch toughness characteristics and is ideal for use in lower than ambient temperature services. Chemical analysis and tension tests were carried out on the samples. The chemical composition in weight for the SA 333 Gr. 6 steel was $\mathrm{C}=0.124 \%, \mathrm{Mn}=0.919 \%$, $\mathrm{S}=0.001 \%, \mathrm{P}=0.003 \%, \mathrm{Si}=0.314 \%$ and the remainder was Fe and for SA 516 Gr. 70 steel was $\mathrm{C}=0.168 \%, \mathrm{Mn}=1.08 \%$, $\mathrm{S}=0.001 \%, \mathrm{P}=0.004 \%, \mathrm{Si}=0.257 \%, \mathrm{Cr}=0.106 \%, \mathrm{Mo}=0.03 \%$ and the remainder was Fe.

Mechanical properties of the samples were determined by carrying out tension tests by using a $\pm 250 \mathrm{kN}$ capacity Universal Testing Machine (UTM) as per ASTM E 8M [10]. Table 1 gives the mechanical properties of both the materials.

TABLE 1

Mechanical properties of SA 333 Gr. 6 and SA 516 Gr. 70 steel

\begin{tabular}{|c|c|c|c|c|}
\hline \multirow{2}{*}{ Properties } & \multicolumn{2}{|c|}{ Experimental } & \multicolumn{2}{c|}{$\begin{array}{c}\text { Value as per } \\
\text { ASTM (min.) }\end{array}$} \\
\cline { 2 - 5 } & $\begin{array}{c}\text { SA 333 } \\
\text { Gr. 6 }\end{array}$ & $\begin{array}{c}\text { SA 516 } \\
\text { Gr.70 }\end{array}$ & $\begin{array}{c}\text { SA 333 } \\
\text { Gr. 6 }\end{array}$ & $\begin{array}{c}\text { SA 516 } \\
\text { Gr. 70 }\end{array}$ \\
\hline Yield strength, $\sigma_{y}(\mathrm{MPa})$ & 310 & 330 & 240 & 260 \\
\hline $\begin{array}{c}\text { Ultimate tensile strength, } \\
\sigma_{u}(\mathrm{MPa})\end{array}$ & 465 & 530 & 415 & $485-620$ \\
\hline $\begin{array}{c}\text { Modulus of elasticity, } \\
E(\mathrm{GPa})\end{array}$ & 205 & 200 & - & - \\
\hline Elongation $(\%)$ & 28.00 & 19.20 & 16.50 & 17 \\
\hline
\end{tabular}

\section{Experimental studies}

\subsection{Specimen details}

ASTM E 647-13 [11] recommends mainly three types of specimens, viz., Compact [C(T)] specimen, Middle Tension $[\mathrm{M}(\mathrm{T})]$ specimen, Eccentrically-loaded Single Edge notch Tension $[\mathrm{ESE}(\mathrm{T})]$ specimen for carrying out FCG studies on materials. In the present studies, ESE(T) specimen was used. The main advantages of $\operatorname{ESE}(\mathrm{T})$ specimens are it gives additional working space and its design reduces the T-stress (stress parallel to the crack surface) and crack fracture paths are more self-similar than the other specimens. It is recommended that the thickness of the $\mathrm{ESE}(\mathrm{T})$ specimen be in the range of $(W / 20) \leq B \leq(W / 4)$. Where $W$ is the width of the specimen, $B$ is the thickness of the specimen.

The ESE(T) specimen made of SA 333 Gr. 6 steel was fabricated from a straight pipe having a length of $525 \mathrm{~mm}$, outer diameter $415 \mathrm{~mm}$ and wall thickness $32 \mathrm{~mm}$. The other ESE(T) specimen made of SA 516 Gr. 70 steel was fabricated from a plate of thickness $25 \mathrm{~mm}$. The SA 333 Gr. 6 and SA 516 Gr. 70 steels were machined to get specimens of dimensions $277.5 \mathrm{~mm} \times 75 \mathrm{~mm} \times 8 \mathrm{~mm}$. A straight machined notch of length $11.25 \mathrm{~mm}$ was made by electrical discharge machining process at the mid height of these specimens. Details of ESE(T) specimen is shown in Fig. 1. 


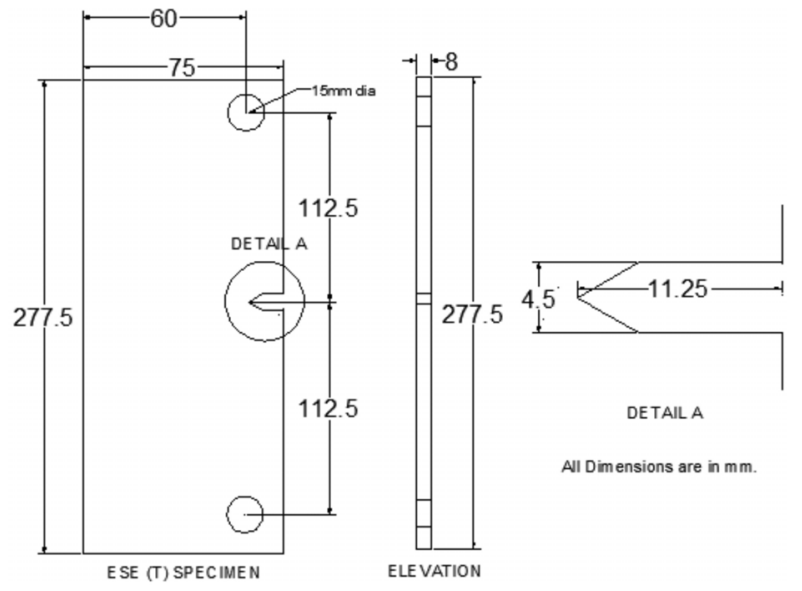

Fig. 1. Deatails of $\operatorname{ESE}(\mathrm{T})$ specimen

\subsection{Test detail}

Corrosion fatigue crack growth experiments were carried out by using a servo-hydraulic fatigue rated UTM of $\pm 250 \mathrm{kN}$ capacity. A corrosion chamber made of Perspex sheet was fixed to the test specimen at the notch portion; chamber contained distilled water to a depth of $45 \mathrm{~mm}$.

All the experiments were carried out under constant amplitude sinusoidal cyclic loading and the stress ratio was maintained as 0.1 . The maximum and minimum load values were $15 \mathrm{kN}$ and $1.5 \mathrm{kN}$, which were decided based on ASTM E 1820 [12]. Crack growth in the length direction was continuously monitored and images were recorded at regular intervals of loading cycles. The number of cycles for crack initiation was recorded for both the specimens. The experiments were continued till the crack growth in the specimens become unstable. Fig. 2 shows the setup for CFCG experiment on an ESE(T) specimen. Fig. 3 shows close-up view of the ESE(T) specimen and corrosion chamber. For the FCG results to be valid, it is required that the specimen be predominantly elastic at all values of applied force.

Eq. (1) recommended in ASTM E 647-13 [11] was used to check the elastic condition in the $\operatorname{ESE}(\mathrm{T})$ specimen at different cycles of loading.

$$
(W-a) \geq(4 / \pi)\left(K_{\max } / \sigma_{y s}\right)^{2}
$$

Where $(W-a)=$ uncracked ligament $\mathrm{mm} ; K_{\max }=$ maximum stress intensity factor, $\mathrm{MPa} \sqrt{\mathrm{mm}}$ and $\sigma_{y s}=$ yield strength, $\mathrm{MPa}$.

Crack growth rate $(d a / d N)$ and stress intensity factor range $(\Delta K)$ values were evaluated at incremental values of crack length. Stress intensity factor range $(\Delta K)$ values were evaluated using the following expressions given in ASTM E 647-13 [11].

$$
\begin{gathered}
\Delta K=[\Delta P /(B \sqrt{ } W)] F \\
F=\alpha^{1 / 2}[1.4+\alpha][1-\alpha]^{-3 / 2} G
\end{gathered}
$$

Where,

$$
\begin{aligned}
G= & 3.97-10.88 \alpha+26.25 \alpha^{2}-38.9 \alpha^{3}+ \\
& +30.15 \alpha^{4}-9.27 \alpha^{5} \\
\Delta P= & \text { load range } ; \alpha=a / W, \text { for } 0<\alpha<1 .
\end{aligned}
$$

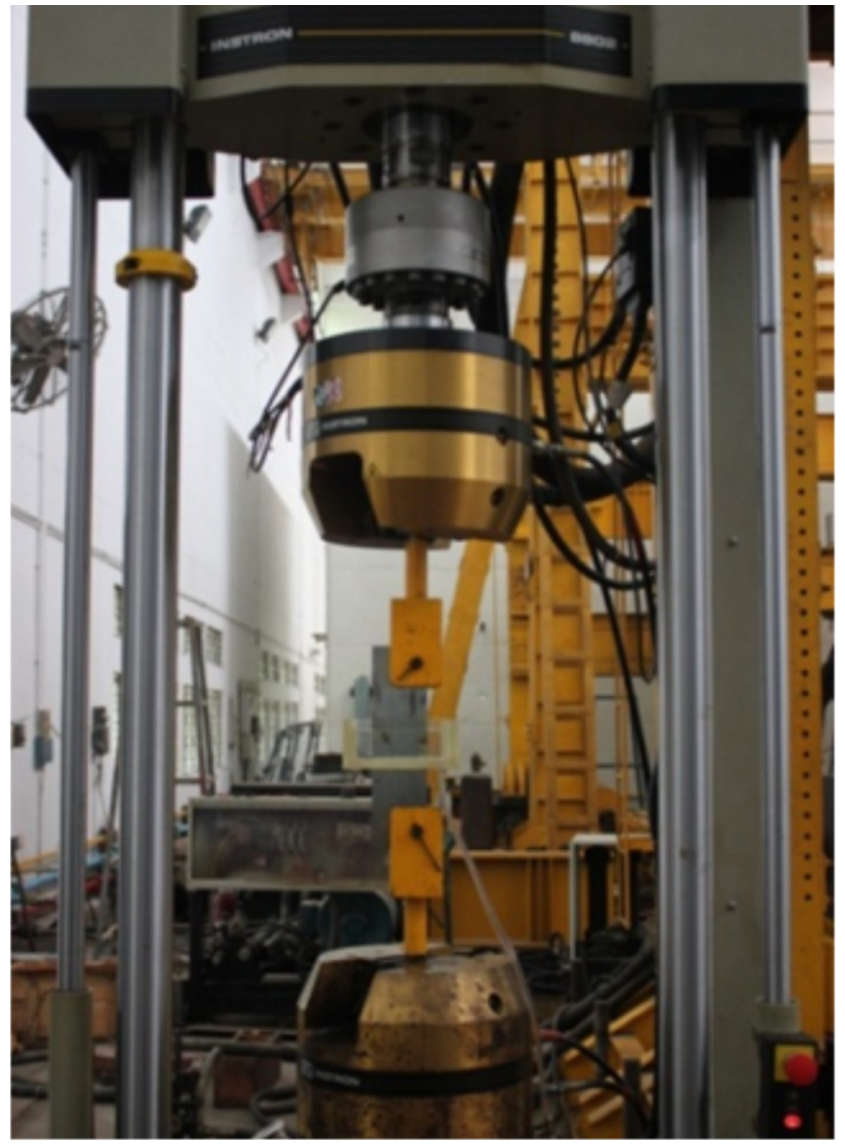

Fig. 2. Set-up of CFCG experiment on an $\operatorname{ESE}(\mathrm{T})$ specimen

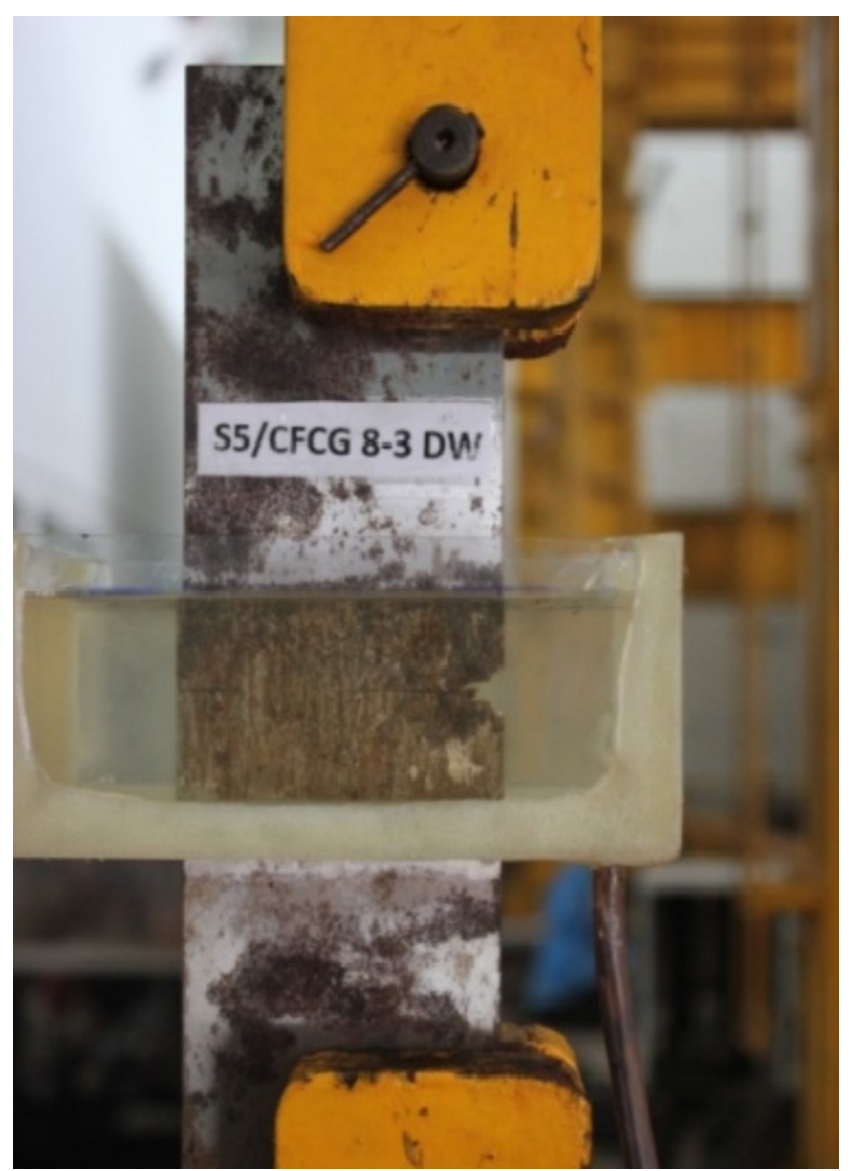

Fig. 3. Close-up view of the ESE(T) specimen and corrosion chamber 


\section{Results and discussion}

Table 2 gives number of cycles to crack initiation, end of the experiment, and the corresponding crack length including initial notch length for the $\operatorname{ESE}(\mathrm{T})$ specimen. The tests were terminated when the crack growth in the specimens became unstable and the uncracked ligament was insufficient to take further load. Figs. 4 and 5 shows crack growth images for the specimen S3/CFCG8-4DW (made of SA 333 Gr. 6 steel) and specimen S5/CFCG8-3W (made of SA 516 Gr. 70 steel) respectively. Fig. 6 shows crack length vs. number of cycles for the specimens S3/CFCG8-4DW and S5/CFCG8-3DW. Fatigue crack growth rate of SA 516 Gr. 70 steel was observed to be more when compared with SA 333 Gr. 6 steel specimen. From Table 2, it can be observed that for the specimen S3/CFCG8$4 \mathrm{DW}$, crack initiated at 60,000 cycles and the specimen failed at $3,65,292$ cycles. The corresponding length of crack was 57.70 $\mathrm{mm}$ (including the initial notch length). In the case of specimen S5/CFCG8-3DW, crack initiated at 70,000 cycles and the specimen failed at 3,16,426 cycles. The corresponding length of crack was $57.05 \mathrm{~mm}$ (including the initial notch length). The number of cycles corresponding to the maximum crack length

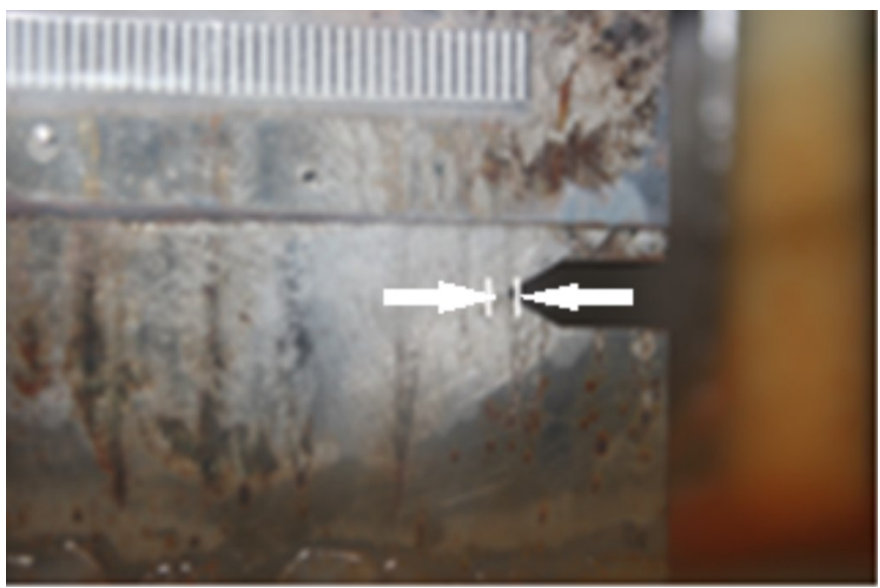

a)

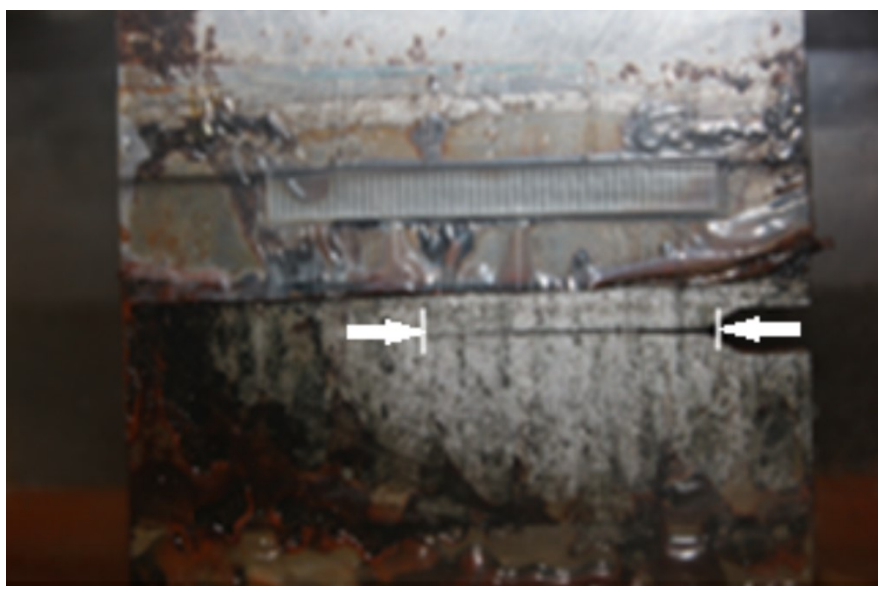

c) satisfying elastic check criteria was $3,55,000$ cycles for the specimen S3/CFCG8-4DW and 3,10,000 cycles for the specimen S5/CFCG8-3DW.

TABLE 2

Results of corrosion fatigue tests

\begin{tabular}{|c|c|c|c|c|c|}
\hline \multirow[b]{2}{*}{$\begin{array}{c}\text { Specimen } \\
\text { ID }\end{array}$} & \multicolumn{2}{|c|}{ Crack initiation } & \multirow{2}{*}{\begin{tabular}{|c|} 
No of cycles \\
satisfying \\
elastic \\
check
\end{tabular}} & \multicolumn{2}{|c|}{ End of Experiment } \\
\hline & $\begin{array}{l}\text { Number } \\
\text { of cycles }\end{array}$ & $\begin{array}{c}\text { Crack } \\
\text { length* } \\
\text { mm } \\
\end{array}$ & & $\begin{array}{l}\text { Number } \\
\text { of cycles }\end{array}$ & $\begin{array}{c}\text { Crack } \\
\text { length* } \\
\text { mm } \\
\end{array}$ \\
\hline \begin{tabular}{|c|}
$\mathrm{S} 3 / \mathrm{CFC}$ \\
$\mathrm{G} 8-4 \mathrm{DW}$
\end{tabular} & 60,000 & 0.6 & $3,55,000$ & $3,65,292$ & 57.70 \\
\hline \begin{tabular}{|c|} 
S5/CFC \\
G8-4DW
\end{tabular} & 70,000 & 0.4 & $3,10,000$ & $3,16,426$ & 57.05 \\
\hline
\end{tabular}

Plots between $d a / d N$ and $\Delta K$ were obtained for both the specimens as shown in Figs. 7 and 8. Using the crack growth rate $(d a / d N)$ vs. stress intensity factor range $(\Delta K)$ plots, best fit curves following power law in the form of Paris' equation were obtained. TABLE 3 gives the fatigue crack growth constants for SA 333 Gr. 6 and SA 516 Gr. 70 steels.

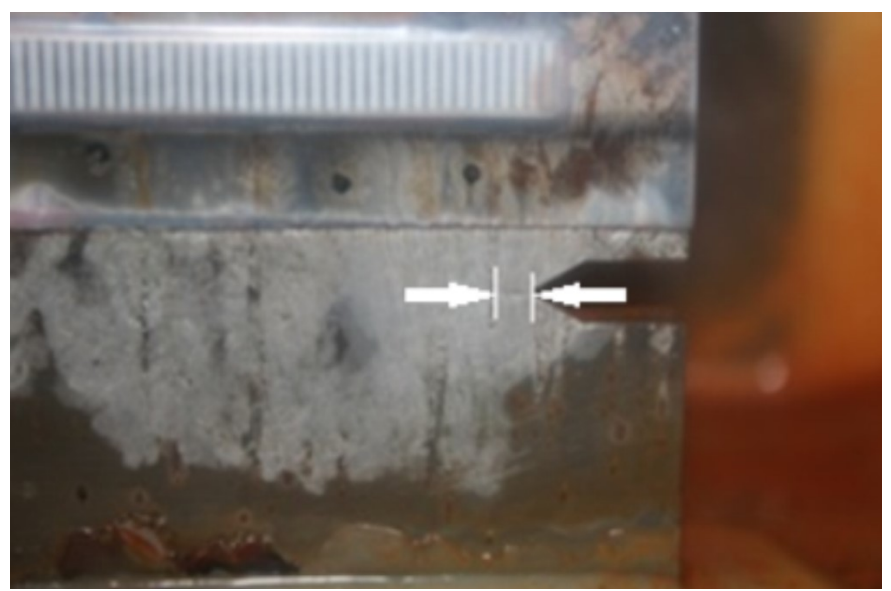

b)

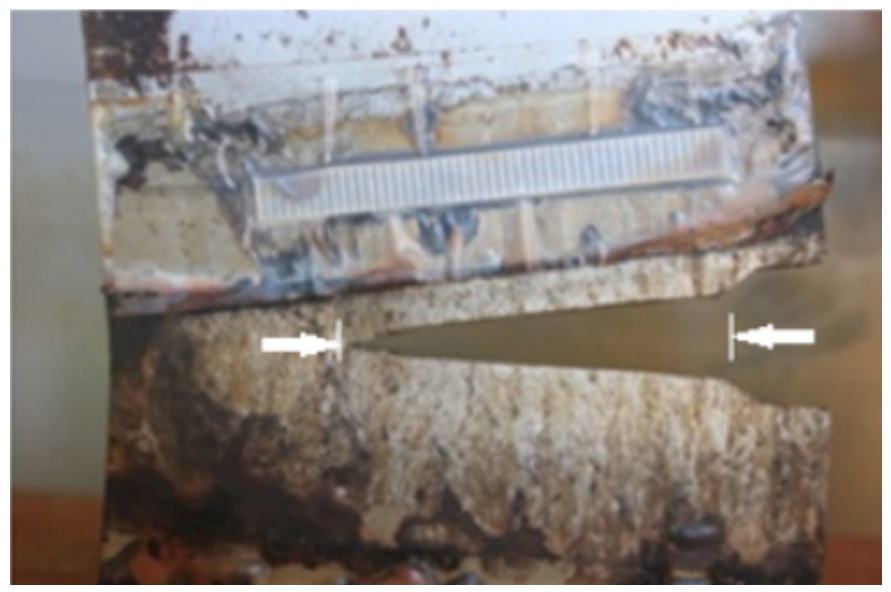

d)

Fig. 4. Crack growth images for the specimen S3/CFCG8-4DW 


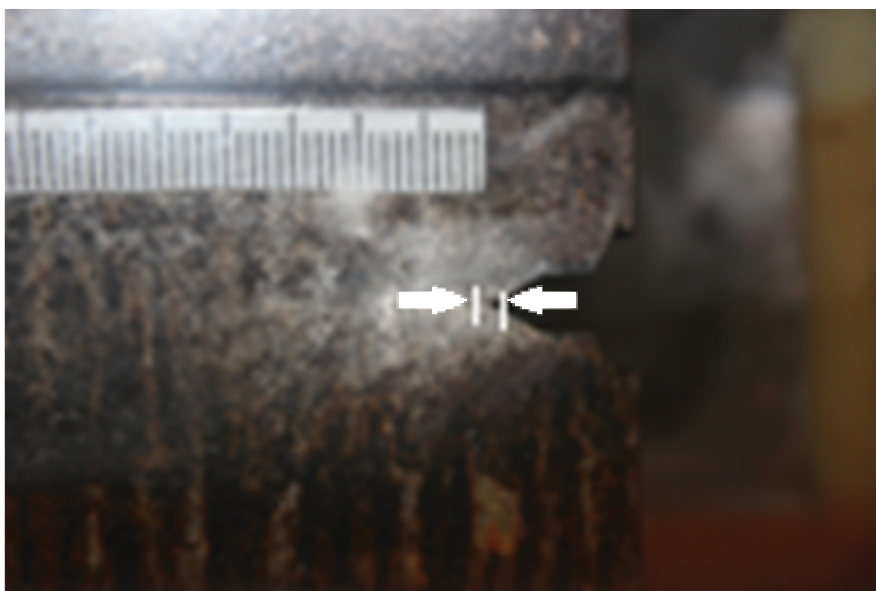

a)

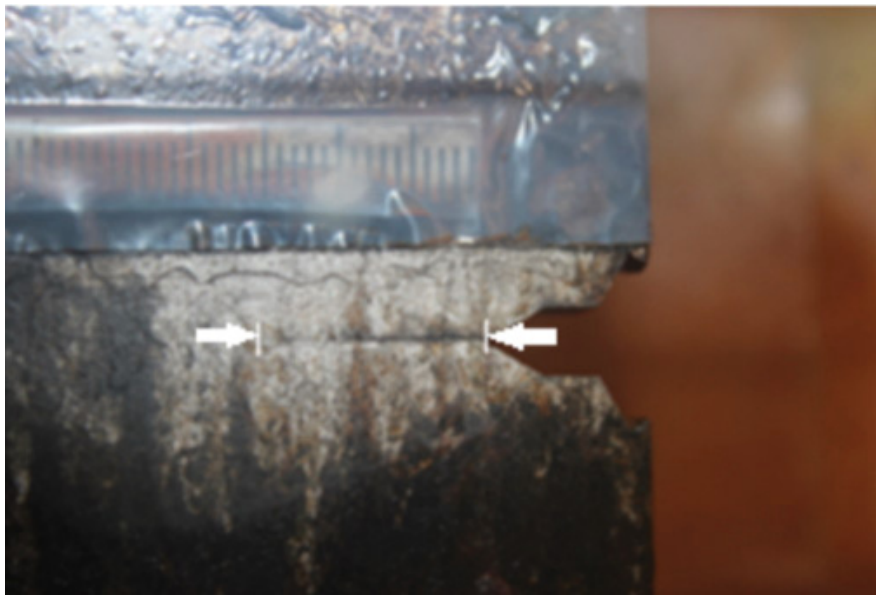

c)

Fig. 5. Crack growth images for the specimen S5/CFCG8-3DW

TABLE 3

Fatigue crack growth constants for SA333 Gr. 6 and SA 516 Gr. 70 steels

\begin{tabular}{|c|c|c|}
\hline \hline FCG constants & S3/CFCG8-4DW & S5/CFCG8-3DW \\
\hline$C$ & $5 \times 10^{-9}$ & $8 \times 10^{-9}$ \\
\hline$m$ & 3.223 & 3.098 \\
\hline
\end{tabular}

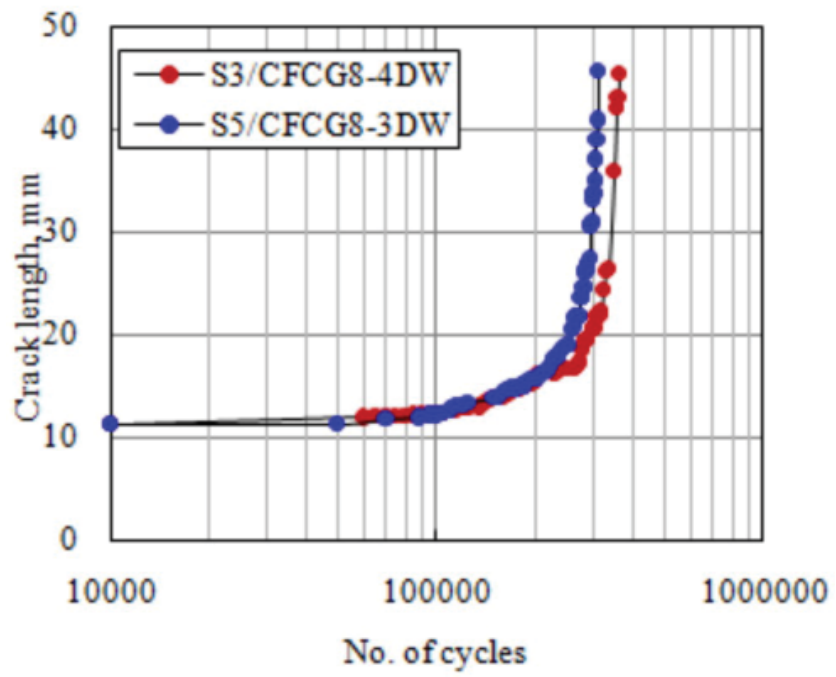

Fig. 6. Crack length vs. no. of cycles

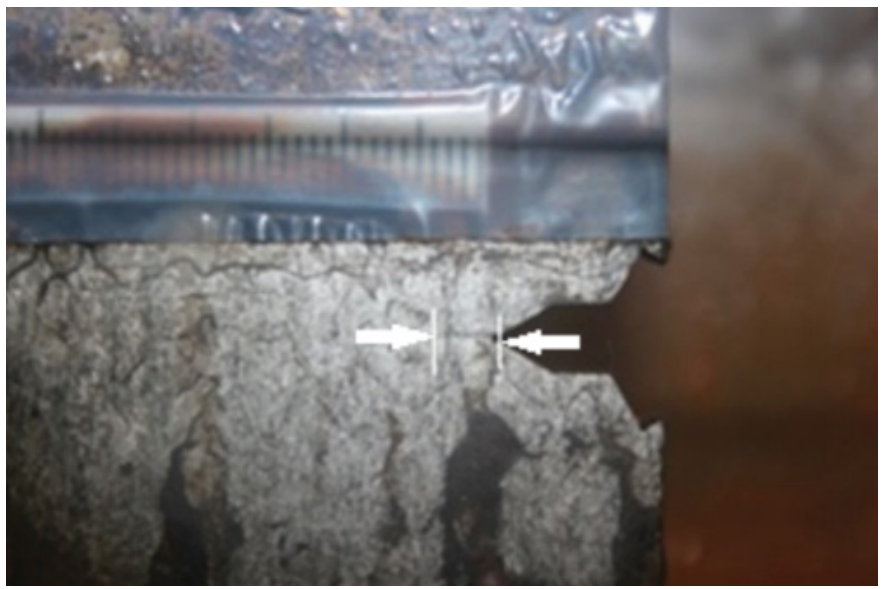

b)

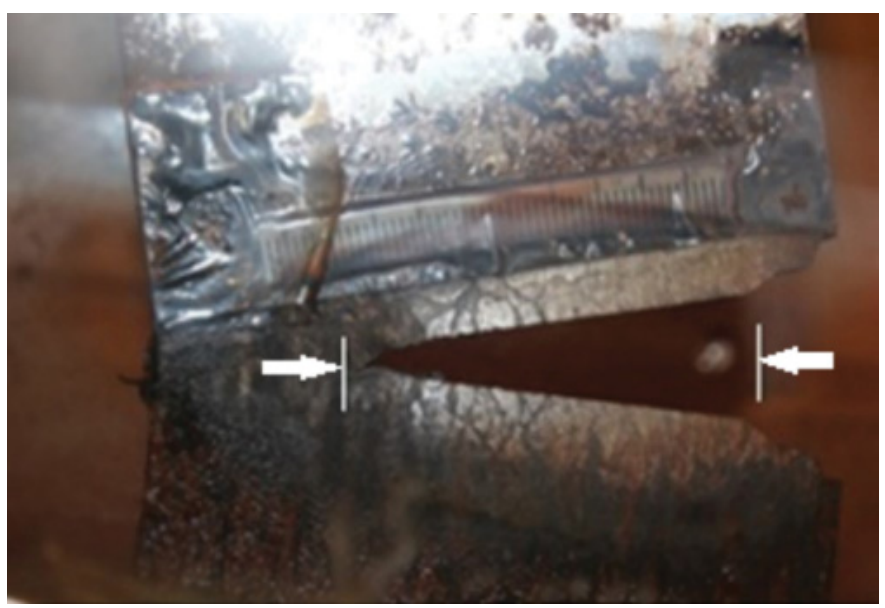

d)

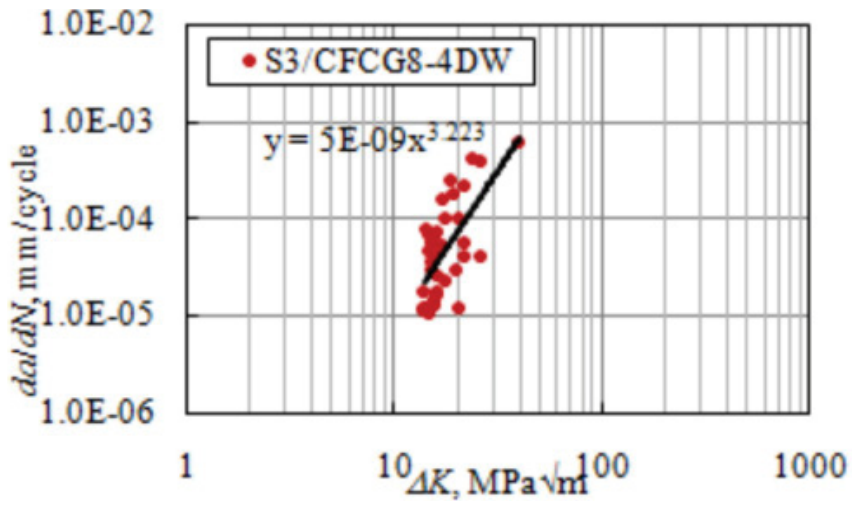

Fig. 7. Crack growth rate vs. stress intensity factor range for the specimen S3/CFCG8-4DW

\section{Summary and conclusion}

Corrosion fatigue crack growth (CFCG) studies were carried out on ESE(T) specimens made of SA 333 Gr. 6 and SA 516 Gr. 70 steels in distilled water environment. During the CFCG experiments, crack initiation and growth were continuously monitored and images were recorded at regular intervals of loading cycles. Fatigue crack growth rate in SA 516 Gr. 70 steel was observed to be more when compared with that in SA 


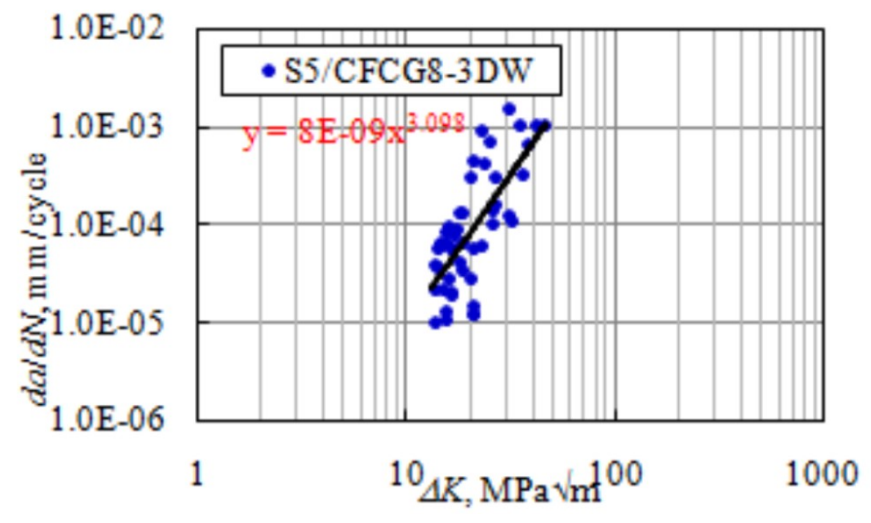

Fig. 8. Crack growth rate vs. stress intensity factor range for the specimen S5/CFCG8-3DW

333 Gr. 6 steel. Crack growth rate $(d a / d N)$ and stress intensity factor range $(\Delta K)$ values were evaluated at incremental values of crack length. Using the crack growth rate $(d a / d N)$ vs. stress intensity factor range $(\Delta K)$ plots, best fit curves following power law in the form of Paris' equation were obtained.

\section{Acknowledgment}

The first author thanks the Director, CSIR-SERC, Chennai for permitting her to carry out her M.Tech. project work at CSIR-SERC based on which this paper has been prepared. The authors from CSIR-SERC thank the
Director and Advisor (Management), CSIR-SERC for the constant support and encouragement extended to them in their R\&D activities. This paper is published with the kind permission of the Director, CSIR-SERC, Chennai.

\section{REFERENCES}

[1] ASTM E 742-1981, ASTM International. USA.

[2] J.Y. Huang, J.J. Yeh, R.C. Kuo, S.L. Jeng, M.C. Young, International Journal of Pressure Vessels and Piping (2008).

[3] Ch. Madduri, R.V.Prakash, International journal of Mechanical and Material Science 4, 399-404 (2010).

[4] Jamasri, M.N. Ilman, R. Seokrisno, Triyono, Engg. Proced. 10, 649-654 (2011).

[5] G. Raghava, S. Vishnuvardhan, P. Gandhi, First International Conference on Structural Integrity, Kalpakkam 2014.

[6] S. Vishnuvardhan, G. Raghava, M. Saravanan, P. Gandhi, CORCON, Chennai 2015.

[7] P.S. Aarthi, G. Raghava, S. Vishnuvardhan, M. Surendar, International Journal of Innovative Research in Science, Engineering and Technology 4 (6), 1687-1696 (2015).

[8] ASTM A 333-05, ASTM International, USA.

[9] ASTM A 516-10, ASTM International. USA.

[10] ASTM E 8M-11, ASTM International. USA.

[11] ASTM E 647-13, ASTM International. USA.

[12] ASTM E 1820-13, ASTM International. USA. 